\title{
Comparison of prognosis according to tumor size in papillary thyroid carcinoma with lateral cervical node metastasis
}

Kwan Ho Lee

Eunpyeong St.Mary's hospital https://orcid.org/0000-0002-6526-3333

Ji Sup Yun ( $\square$ subi0117@naver.com )

Eun Young Kim

Kangbuk Samsung Medical Center

Chan Heun Park

Kangbuk Samsung Medical Center

Yong Lai Park

Kangbuk Samsung Medical Center

Research article

Keywords:

Posted Date: August 30th, 2019

DOI: https://doi.org/10.21203/rs.2.13768/v1

License: (1) (i) This work is licensed under a Creative Commons Attribution 4.0 International License.

Read Full License 


\section{Abstract}

Background: Lateral lymph node metastasis (LNM), which significantly impacts papillary thyroid carcinoma (PTC) patients' prognosis, occurs not uncommonly in papillary thyroid microcarcinoma (PTMC). PTMC is known to have a much better prognosis than non-PTMC, but it has not been known whether there is such a difference even with lateral LNM. Methods: This retrospective study included a series of 3336 consecutive PTC patients who underwent thyroidectomy. Of them, 206 had lateral LNM and were divided into the PTMC and non-PTMC groups by tumor size $(1-\mathrm{cm})$ for comparing the prevalence of prognostic factors. Results: LNM was in 157/1131 (13.9\%) non-PTMC patients and 49/2205 (2.2\%) PTMC patients. Eleven of the 206 (5.3\%) lateral LNM cases not found on US were only seen on computed tomography. The prevalence of prognostic factors which include an age of $>55$ years, $>5$ metastatic lymph nodes (LNs), high metastatic-to-examined LN ratio, and large metastatic LNs (>3 $\mathrm{cm}$ ) were not significantly different between PTMC and non PTMC group. Conclusions: In PTC with lateral LNM, the prognosis is likely to be similar regardless of tumor size. Considering the modest risk of lateral LNM in PTMC, FNA and detailed radiologic for small tumor should be encouraged.

\section{Background}

Papillary thyroid carcinoma (PTC) accounts for $90 \%$ of all thyroid carcinomas, and its prevalence is increasing owing to the recent development and dissemination of ultrasonography (US) and US-guided fine needle aspiration (FNA).[1, 2] Papillary thyroid microcarcinoma (PTMC) refers to a cancer with a maximum tumor diameter of $\leq 10 \mathrm{~mm}$; most PTMCs have been reported to have a good prognosis.[3] In the recently published 2015 American Thyroid Association (ATA) guidelines, if the size of the nodule is $<1$ $\mathrm{cm}$, FNA should not be performed even if the US findings are highly suspicious of malignancy.[4] In addition, some studies have suggested that active surveillance is a better option for patients with PTMC than immediate surgery.[5, 6]PTC is characterized by frequent lymphatic metastases. It has been reported that lymph node metastasis (LNM) develops in approximately $30 \%$ to $80 \%$ of patients with PTC.[7] The incidence of LNM in PTMC is known to range from $3.1 \%$ to $81 \%$, although it differs among studies.[8] In particular, lateral LNM has a significant impact on patients' prognosis $[9,10]$ and is present in 3.7 to $55 \%$ of PTMC.[8, 11-16]. PTMC is known to have a much better prognosis than non-PTMC, but it has not been known whether there is such a difference even with LNM. We supposed that if tumors $<1-\mathrm{cm}$ was not performed histologic examination according to the current guidelines, LNM may not be detected considering that most clinicians do not make enough effort, such as performing computed tomography (CT) or US for lateral neck node assessment in patients without the histologic diagnosis as PTC. As such, the appropriate timing of the diagnosis and treatment of lateral LNM is likely to be missed, and the patients' prognosis may be adversely affected.The number and size of metastatic lymph nodes (LNs) in the neck are known as important predictors of the prognosis of patients with PTC with lateral LNM.[17] In addition, the ratio of metastatic LNs to the examined LNs (LNR) has been proposed as an important predictor of recurrence.[18-20]Therefore, we investigated the incidence of lateral LNM in PTC in our center and compared the characteristics between PTMC with lateral LNM and non-PTMC with lateral LNM. We 
also investigated the prevalence of prognostic factors of PTC with lateral LNM, which were previously known in previous studies, and compared their differences between the PTMC group and non-PTMC group.

\section{Methods}

We retrospectively collected the clinico-pathologic data of 3,392 patients diagnosed with PTC who underwent thyroidectomy in our center from January 2008 to December 2015. The exclusion criteria consisted of history of thyroidectomy $(n=38)$, concurrent medullary or anaplastic thyroid carcinoma $(n=4)$, and follow-up loss $(n=14)$. Finally, 3,336 patients were enrolled in this study. Of them, 206 patients underwent prophylactic/therapeutic bilateral central compartment neck (level VI; pretracheal, prelaryngeal, and paraesophageal LNs) dissection and therapeutic lateral cervical neck (levels Ila, III, IV, and Vb, not including the sternocleidomastoid, jugular vein, and accessory nerve) dissection (LCND) after lateral LNM was diagnosed on the basis of the preoperative examination findings. These patients were divided into the PTMC and non-PTMC groups. All patients were diagnosed using US-guided FNA biopsy for thyroid nodules before surgery. To confirm the presence of LNM, real-time US and contrast-enhanced CT were performed; all images were assessed by 1 of 3 radiologists who specialize in diseases of the neck and thyroid with $>5$ years of experience. FNA was performed on the suspicious lateral neck LN for metastasis assessment on US, which was defined as follows: hyper-echogenicity (higher than the surrounding muscles), cystic change, loss of fatty hilum, calcification, round shape, and abnormal vascular pattern. [21-23] If the cytology for FNA revealed metastatic LNs or thyroglobulin in the LNs with a washout fluid level of $\geq 10 \mathrm{ng} / \mathrm{dL}$, the condition was diagnosed as a metastatic $L N$. If not visible on US but strongly suspected on CT, the selective node that was grossly enlarged or had a suspicious feature was excised; intraoperative frozen biopsy before LCND then followed. The suspicious CT features were as follows: presence of calcifications, central necrosis or cystic change, and heterogeneous cortical enhancement or enhancement more than that of the adjacent muscle.[22, 23] As recommended in the ATA guidelines,[4] prophylactic LCND was not performed. This study was approved by the Institutional Review Board of Kangbuk Samsung Hospital (KBSMC 2017-04-037).

\section{Clinico-pathologic analysis}

We compared the incidence of lateral LNM between the PTMC and non-PTMC groups and analyzed their clinico-pathologic factors. In addition, the prognostic difference between the 2 groups was indirectly analyzed by comparing the differences in the factors affecting the prognosis, which were demonstrated in previous studies.[20,24] Ito et al.[24] reported that patients under the N1b stage who underwent LCND had a high recurrence rate if they were older than 55 years or had a metastatic node size of $\geq 3 \mathrm{~cm}$. In other patients, the LNR was helpful in predicting the prognosis in addition to the number and size of metastatic LNs. Lee et al.[20] reported that the LNR (levels II-VI) had a cutoff value of 0.5, which was associated with patients' prognosis. Park et al.[20] reported that the loco-regional recurrence-free survival 
was affected by the presence of $>6$ metastatic nodes and by a cutoff value of 0.22 for the LNR. Based on these previous results, the differences between the 2 groups were compared using the clinico-pathologic data of the patients in this study.

\section{Statistical analysis}

All statistical analyses were performed using $\mathrm{R}$ version 3.3.2.[22, 23, 25-28] For comparison between the PTMC and non-PTMC groups, the t-test for continuous variables and Fisher's exact test or Chi-square test for categorical variables were used.

\section{Results}

Of the total 3,336 patients with PTC, 2,205 (66.1\%) had PTMC, and 1,131 (33.9\%) had non-PTMC. Further, 206 patients $(6.2 \%)$ had lateral LNM and consequently underwent therapeutic LCND. LCND was performed in 157 of the 1,131 (13.9\%) non-PTMC patients and 49 of the 2,205 (2.2\%) PTMC patients (Fig. 1). These patients who underwent LCND were divided into the PTMC and non-PTMC groups; the differences in the clinico-pathologic factors are summarized in Table 1. The proportion of men tended to be higher in the PTMC group (PTMC: $42.9 \%$ vs non-PTMC: $27.4 \%, p=0.062$ ). The pathologic tumor size of the PTMC group was $0.7 \pm 0.3 \mathrm{~cm}$, and that of the non-PTMC group was $1.9 \pm 0.8 \mathrm{~cm}$. The largest size of the metastatic LNs was $1.1-\mathrm{cm}$ in the PTMC group and $1.3 \mathrm{~cm}$ in the non-PTMC group; however, the difference was not significant $(p=0.188)$. The multifocality, bilaterality, vascular invasion, and BRAF mutation were not significantly different between the 2 groups as well. Only the percentages of gross extrathyroidal extension $(p<0.001)$ and lymphatic invasion $(p=0.047)$ were significantly higher in the nonPTMC group.

\section{Comparison of the clinico-pathologic factors affecting the prognosis}

We compared the differences in the predictive factors of recurrence, which were demonstrated to be associated with patients' prognosis in previous studies on patients who underwent LCND with lateral LNM and the 2015 ATA guidelines. $[4,20,24]$ An age of $>55$ years, $>5$ metastatic LNs, high LNRs (cutoff value: 0.22 and 0.5$)$, and large metastatic $L N s(>3 \mathrm{~cm})$, which were factors related to a poor prognosis, were slightly more in the non-PTMC group; however, the difference was not significant (Table 2).

Necessity for detailed imaging studiesIn our institution, radiologists with an experience of $>5$ years and a specialization in thyroid imaging performed US and assessed the CT images. Neck US and CT for preoperative staging were performed in all patients diagnosed with thyroid cancer after FNA. Nevertheless, the number of patients with lateral LNM not found on US was 4 (8.2\%) in the PTMC group and 7 (4.5\%) in the non-PTMC group; that of patients with lateral LNM not found on CT was $5(10.2 \%)$ in 
the PTMC group and 21 (13.4\%) in the non-PTMC group (Fig. 2). This result shows the possibility of not detecting lateral LNM if only CT or US is performed.

\section{Discussion}

Because of the recent rapid increase in the number of diagnoses and surgeries performed for thyroid cancer, several studies have questioned the need for indolent PTMC surgery, and there has been a controversy regarding the clinical necessity for FNA for small thyroid nodules.[29, 30] The 2015 ATA guidelines recommended against FNA for thyroid nodules smaller than 1-cm, even for those with highly suspicious US patterns.[4] Although this is limited to cases not accompanied by extrathyroidal extension or suspicious cervical LN, many clinicians questioned this guideline.Although PTMC is a small-sized cancer of $<1-\mathrm{cm}$ in diameter and is an indolent cancer, it has been reported that $3.1 \%$ to $18.2 \%$ of lateral LNM and up to $20 \%$ of loco-regional recurrences exist.[31-33] Lateral LNM requires patients to undergo a wide-extent surgical procedure, resulting in a higher morbidity.[9, 34] In addition, it is a crucial risk factor for distant metastasis, which is associated with increased mortality. $[10,35]$ However, although there is a difference among institutions, careful examination of the lateral nodes is not always performed in patients without a pathologic diagnosis of PTC. There is a possibility that the diagnosis of lateral LNM can be missed if $<1-\mathrm{cm}$ tumors are not pathologically confirmed, which may be the reason for encouraging FNA of suspicious $\leq 1-\mathrm{cm}$ nodules. The ATA guidelines recommend preoperative neck US for cervical (central and especially lateral neck compartment) LNs for all patients undergoing thyroidectomy for malignant or suspicious for malignant cytologic or molecular findings.[4] US is a very useful test for the detection of thyroid diseases and cervical lymphadenopathy and the most recommended technique for detecting LNM. However, the accuracy rate of cervical LN evaluation has been known to be $\sim 48.1 \%$, [36] and the diagnostic values for lateral LNM showed a wide range in various studies (sensitivity, 64$95 \%$; specificity, $50-97.9 \%) .[22,23,28,37]$ It is because US is an operator-dependent examination and utilized by physicians in various specialties, including radiologists, endocrinologists, and surgeons. The consensus on the usefulness of using neck CT in addition to US in detecting lateral LNM remains unclear. $\mathrm{CT}$ is not recommended for routine use for preoperative staging of differentiated thyroid cancer and is only considered if advanced cancer is suspected.[4, 22,38] Kim et al.[22] demonstrated that US/CT combination was superior to US alone in the detection of metastatic LNs in the lateral neck. Conversely, Yoon et al.[28] proved that CT does not provide additional diagnostic values when combined with US in the diagnosis of LNM. In our study, 11 of the 206 (5.3\%) cases of lateral LNM not found on US were only seen on CT. Therefore, further research on the usefulness of CT in PTC is needed. The strength of this study is that it minimized selection bias because both CT and US were performed for preoperative staging in all patients diagnosed with thyroid cancer in our institution. Conversely, the limitation of this study is the indirect prognostic analysis through comparison of known prognostic factors. Therefore, a direct prognostic observation is needed.

\section{Conclusions}


The incidence of lateral LNM in PTMC was $2.2 \%$, which is lower than previously reported results (3.7$55 \%),[8,11-16]$ but is thought to be a relatively high value when considering the known indolent nature of PTMC. There was also no significant difference in the prevalence of clinico-pathologic factors with prognostic values between the PTMC and non-PTMC groups with lateral LNM. This suggests that lateral LNM in PTMC does not seem to have a better prognosis than that in non-PTMC. In addition, considering the various US sensitivities among practitioners, there is a considerable risk of misdiagnosis in the preoperative assessment of cervical LNs. Therefore, if suspicious $<1-\mathrm{cm}$ thyroid nodules are found, it may be necessary to consider FNA, and if diagnosed with cancer, including PTMC, detailed radiologic examinations for cervical LNs should be encouraged.

\section{Abbreviations}

ATA: American Thyroid Association; US: ultrasonography; CT: computed tomography; FNA: fine needle aspiration; LCND: lateral cervical neck dissection; LNM: lymph node metastasis; LNs: lymph nodes; PTC: papillary thyroid carcinoma; PTMC: papillary thyroid microcarcinoma

\section{Declarations}

\section{Ethics approval and consent to participate}

This study was approved by the Institutional Review Board of Kangbuk Samsung Hospital, the Sungkyunkwan University of Korea, on 8 April 2017 (KBSMC 2017-04-037). The institutional review board waived the need for written informed consent from the participants as the project was deemed to be in the low or negligible risk category in accordance with the Korean National Bioethics Committee 'National Statement on Ethical Conduct in Human Research', 2017.

\section{Consent for publication}

Not applicable.

\section{Availability of data and materials}

The datasets used and/or analyzed during the current study are available from the corresponding author on reasonable request.

\section{Competing interests}

The authors declare that they have no competing interests. 


\section{Funding}

None declared.

\section{Authors' contributions}

EYK, YLP and JSY collected and interpreted the patient data, and KHL was a major contributor in writing the manuscript. CHP inspired the topic selection and led the authors. All authors read and approved the final manuscript.

\section{Acknowledgements}

Not applicable.

\section{References}

1. Renshaw AA. Papillary carcinoma of the thyroid $<0 r=1.0 \mathrm{~cm}$ : rarely incidental or occult any more. Cancer. 2005;105(4):217-9.

2. Hughes DT, Haymart MR, Miller BS, Gauger PG, Doherty GM. The most commonly occurring papillary thyroid cancer in the United States is now a microcarcinoma in a patient older than 45 years. Thyroid. 2011;21(3):231-6.

3. Yu XM, Wan Y, Sippel RS, Chen H. Should all papillary thyroid microcarcinomas be aggressively treated? An analysis of 18,445 cases. Ann Surg. 2011;254(4):653-60.

4. Haugen BR, Alexander EK, Bible KC, Doherty GM, Mandel SJ, Nikiforov YE, et al. 2015 American Thyroid Association Management Guidelines for adult patients with thyroid nodules and differentiated thyroid cancer: The American Thyroid Association Guidelines task force on thyroid nodules and differentiated thyroid cancer. Thyroid. 2016;26(1):1-133.

5. Ito Y, Miyauchi A, Oda H. Low-risk papillary microcarcinoma of the thyroid: A review of active surveillance trials. Eur J Surg Oncol. 2018;44(3):307-15.

6. Miyauchi A. Clinical trials of active surveillance of papillary microcarcinoma of the thyroid. World $\mathrm{J}$ Surg. 2016;40(3):516-22.

7. Lee YM, Sung TY, Kim WB, Chung KW, Yoon JH, Hong SJ. Risk factors for recurrence in patients with papillary thyroid carcinoma undergoing modified radical neck dissection. $\mathrm{Br} \mathrm{J}$ Surg. 2016;103(8):1020-5.

8. Mehanna H, Al-Maqbili T, Carter B, Martin E, Campain N, Watkinson J, et al. Differences in the recurrence and mortality outcomes rates of incidental and nonincidental papillary thyroid 
microcarcinoma: a systematic review and meta-analysis of 21329 person-years of follow-up. J Clin Endocrinol Metab. 2014;99(8):2834-43.

9. Choi YM, Kim TY, Jang EK, Kwon H, Jeon MJ, Kim WG, et al. Standardized thyroid cancer mortality in Korea between 1985 and 2010. Endocrinol Metab (Seoul). 2014;29(4):530-5.

10. Jeon MJ, Kim WG, Choi YM, Kwon H, Lee YM, Sung TY, et al. Features predictive of distant metastasis in papillary thyroid microcarcinomas. Thyroid. 2016;26(1):161-8.

11. Kwak JY, Kim EK, Kim MJ, Son EJ, Chung WY, Park CS, et al. Papillary microcarcinoma of the thyroid: predicting factors of lateral neck node metastasis. Ann Surg Oncol. 2009;16(5):1348-55.

12. Chung YS, Kim JY, Bae JS, Song BJ, Kim JS, Jeon HM, et al. Lateral lymph node metastasis in papillary thyroid carcinoma: results of therapeutic lymph node dissection. Thyroid. 2009;19(3):241-6.

13. Kim TY, Hong SJ, Kim JM, Kim WG, Gong G, Ryu JS, et al. Prognostic parameters for recurrence of papillary thyroid microcarcinoma. BMC Cancer. 2008;8:296.

14. Wada N, Duh QY, Sugino K, Iwasaki H, Kameyama K, Mimura T, et al. Lymph node metastasis from 259 papillary thyroid microcarcinomas: frequency, pattern of occurrence and recurrence, and optimal strategy for neck dissection. Ann Surg. 2003;237(3):399-407.

15. Zeng RC, Li Q, Lin KL, Zhang W, Gao EL, Huang GL, et al. Predicting the factors of lateral lymph node metastasis in papillary microcarcinoma of the thyroid in eastern China. Clin Transl Oncol. 2012;14(11):842-7.

16. Liu Z, Lei J, Liu Y, Fan Y, Wang X, Lu X. Preoperative predictors of lateral neck lymph node metastasis in papillary thyroid microcarcinoma. Medicine (Baltimore). 2017;96(10):e6240.

17. Jeon MJ, Kim WG, Choi YM, Kwon H, Song DE, Lee YM, et al. Recent changes in the clinical outcome of papillary thyroid carcinoma with cervical lymph node metastasis. J Clin Endocrinol Metab. 2015;100(9):3470-7.

18. Vas Nunes JH, Clark JR, Gao K, Chua E, Campbell P, Niles N, et al. Prognostic implications of lymph node yield and lymph node ratio in papillary thyroid carcinoma. Thyroid. 2013;23(7):811-6.

19. Lee SG, Ho J, Choi JB, Kim TH, Kim MJ, Ban EJ, et al. Optimal cut-off values of lymph node ratio predicting recurrence in papillary thyroid cancer. Medicine (Baltimore). 2016;95(5):e2692.

20. Park YM, Wang SG, Shin DH, Kim IJ, Son SM, Lee BJ. Lymph node status of lateral neck compartment in patients with N1b papillary thyroid carcinoma. Acta Otolaryngol. 2016;136(3):31924.

21. Kim E, Park JS, Son KR, Kim JH, Jeon SJ, Na DG. Preoperative diagnosis of cervical metastatic lymph nodes in papillary thyroid carcinoma: comparison of ultrasound, computed tomography, and combined ultrasound with computed tomography. Thyroid. 2008;18(4):411-8.

22. Ahn JE, Lee JH, Yi JS, Shong YK, Hong SJ, Lee DH, et al. Diagnostic accuracy of CT and ultrasonography for evaluating metastatic cervical lymph nodes in patients with thyroid cancer. World J Surg. 2008;32(7):1552-8. 
23. Choi JS, Kim J, Kwak JY, Kim MJ, Chang HS, Kim EK. Preoperative staging of papillary thyroid carcinoma: comparison of ultrasound imaging and CT. AJR Am J Roentgenol. 2009;193(3):871-8.

24. Ito Y, Kudo T, Takamura Y, Kobayashi K, Miya A, Miyauchi A. Lymph node recurrence in patients with N1b papillary thyroid carcinoma who underwent unilateral therapeutic modified radical neck dissection. World J Surg. 2012;36(3):593-7.

25. R Core Team (2016). R: A language and environment for statistical computing. R Foundation for Statistical Computing, Vienna, Austria. https://www.R-project.org/.

26. Therneau TM (2015). Survival: survival analysis. R package version 2.38. https://CRAN.Rproject.org/package=survival.

27. Therneau TM, Grambsch PM. Modeling survival data: extending the Cox model. New York: Springer; 2010.

28. Yoon JH, Kim JY, Moon HJ, Youk JH, Son EJ, Kim EK, et al. Contribution of computed tomography to ultrasound in predicting lateral lymph node metastasis in patients with papillary thyroid carcinoma. Ann Surg Oncol. 2011;18(6):1734-41.

29. Ito Y, Miyauchi A, Kihara M, Higashiyama T, Kobayashi K, Miya A. Patient age is significantly related to the progression of papillary microcarcinoma of the thyroid under observation. Thyroid. 2014;24(1):27-34.

30. Oda H, Miyauchi A, Ito Y, Yoshioka K, Nakayama A, Sasai H, et al. Incidences of unfavorable events in the management of low-risk papillary microcarcinoma of the thyroid by active surveillance versus immediate surgery. Thyroid. 2016;26(1):150-5.

31. Bramley MD, Harrison BJ. Papillary microcarcinoma of the thyroid gland. Br J Surg. 1996;83(12):1674-83.

32. Harach HR, Franssila KO, Wasenius VM. Occult papillary carcinoma of the thyroid. A "normal" finding in Finland. A systematic autopsy study. Cancer. 1985;56(3):531-8.

33. Pelizzo MR, Boschin IM, Toniato A, Pagetta C, Piotto A, Bernante P, et al. Natural history, diagnosis, treatment and outcome of papillary thyroid microcarcinoma (PTMC): a mono-institutional 12-year experience. Nucl Med Commun. 2004;25(6):547-52.

34. Kim WB. A closer look at papillary thyroid carcinoma. Endocrinol Metab (Seoul). 2015;30(1):1-6.

35. Ghossein R, Ganly I, Biagini A, Robenshtok E, Rivera M, Tuttle RM. Prognostic factors in papillary microcarcinoma with emphasis on histologic subtyping: a clinicopathologic study of 148 cases. Thyroid. 2014;24(2):245-53.

36. Shimamoto K, Satake H, Sawaki A, Ishigaki T, Funahashi H, Imai T. Preoperative staging of thyroid papillary carcinoma with ultrasonography. Eur J Radiol. 1998;29(1):4-10.

37. Hwang HS, Orloff LA. Efficacy of preoperative neck ultrasound in the detection of cervical lymph node metastasis from thyroid cancer. Laryngoscope. 2011;121(3):487-91.

38. Stulak JM, Grant CS, Farley DR, Thompson GB, van Heerden JA, Hay ID, et al. Value of preoperative ultrasonography in the surgical management of initial and reoperative papillary thyroid cancer. Arch 
Surg. 2006;141(5):489-94; discussion 94-6.

\section{Tables}


Table 1 Demographics and clinical characteristics of the patients with PTC and lateral lymph node metastasis by tumor size $(1-\mathrm{cm})$

\begin{tabular}{|c|c|c|c|}
\hline & PTMC $(n=49)$ & Non-PTMC ( $\mathrm{n}=1$ 57) & $\mathrm{p}$ value \\
\hline Age (years) & $46.6 \pm 10.8$ & $47.7 \pm 13.3$ & 0.594 \\
\hline Sex & & & 0.062 \\
\hline Female & $28(57.1)$ & $114(72.6)$ & \\
\hline Male & $21(42.9)$ & $43(27.4)$ & \\
\hline Tumor size $(\mathrm{cm})$ & $0.7 \pm 0.3$ & $1.9 \pm 0.8$ & $<0.001$ \\
\hline Tumor location & & & 0.117 \\
\hline Upper & $22(44.9)$ & $56(35.7)$ & \\
\hline Middle & $24(49.0)$ & $73(46.5)$ & \\
\hline Lower & $3(6.1)$ & $28(17.8)$ & \\
\hline Multifocality & & & 0.185 \\
\hline Absent & $30(61.2)$ & $77(49.0)$ & \\
\hline Present & $19(38.8)$ & $80(51.0)$ & \\
\hline Bilaterality & & & 0.930 \\
\hline Absent & $35(71.4)$ & $109(69.4)$ & \\
\hline Present & $14(28.6)$ & $48(30.6)$ & \\
\hline Lymph node size $(\mathrm{cm})$ & $1.1 \pm 0.7$ & $1.3 \pm 0.8$ & 0.188 \\
\hline Extrathyroidal extension & & & $<0.001$ \\
\hline Absent & $19(38.8)$ & $17(10.8)$ & \\
\hline Microscopic & $27(55.1)$ & $77(49.0)$ & \\
\hline Gross & $3(6.1)$ & $63(40.1)$ & \\
\hline Lymphatic invasion & & & 0.047 \\
\hline Absent & 47 (95.9) & $131(83.4)$ & \\
\hline Present & $2(4.1)$ & $26(16.6)$ & \\
\hline Vascular invasion & & & 1.000 \\
\hline Absent & $48(98.0)$ & 153 (97.5) & \\
\hline Present & $1(2.0)$ & $4(2.5)$ & \\
\hline
\end{tabular}




$\begin{array}{lcc}\text { Negative } & 6(12.2) & 17(10.8) \\ \text { Positive } & 22(44.9) & 63(40.1) \\ \text { Missed } & 21(42.9) & 77(49.0)\end{array}$

Abbreviations: PTC, papillary thyroid carcinoma; PTMC, papillary thyroid microcarcinoma.

Data are expressed as means \pm standard deviations or $\mathrm{n}(\%)$. 
Table 2 Comparison of the clinico-pathologic factors affecting the prognosis of the patients with PTC and lateral lymph node metastasis by tumor size (1-cm)

\begin{tabular}{|c|c|c|c|}
\hline & $\operatorname{PTMC}(\mathrm{n}=49)$ & Non-PTMC (n=157) & $\mathrm{p}$ value \\
\hline Age (years) & & & 0.318 \\
\hline$<55$ & $40(81.6)$ & $115(73.2)$ & \\
\hline$\geq 55$ & 9 (18.4) & $42(26.8)$ & \\
\hline Number of metastatic LN & & & 0.083 \\
\hline$\leq 5$ & $18(36.7)$ & 36 (22.9) & \\
\hline$>5$ & $31(63.3)$ & $121(77.1)$ & \\
\hline LNR, 0.5 & & & 0.344 \\
\hline$\leq 0.5$ & $48(98.0)$ & $146(93.0)$ & \\
\hline$>0.5$ & $1(2.0)$ & $11(7.0)$ & \\
\hline LNR, 0.22 & & & 0.111 \\
\hline$\leq 0.22$ & $26(53.1)$ & $61(38.9)$ & \\
\hline$>0.22$ & $23(46.9)$ & $96(61.1)$ & \\
\hline Largest diameter of metastatic LN (cm) & & & 0.881 \\
\hline$<3$ & $48(98.0)$ & $151(96.2)$ & \\
\hline$\geq 3$ & $1(2.0)$ & $6(3.8)$ & \\
\hline
\end{tabular}

Abbreviations: PTC, papillary thyroid carcinoma; PTMC, papillary thyroid microcarcinoma; LN, lymph node; LNR, lymph node ratio.

Data are expressed as n (\%).

\section{Figures}




\section{Incidence of N1b}

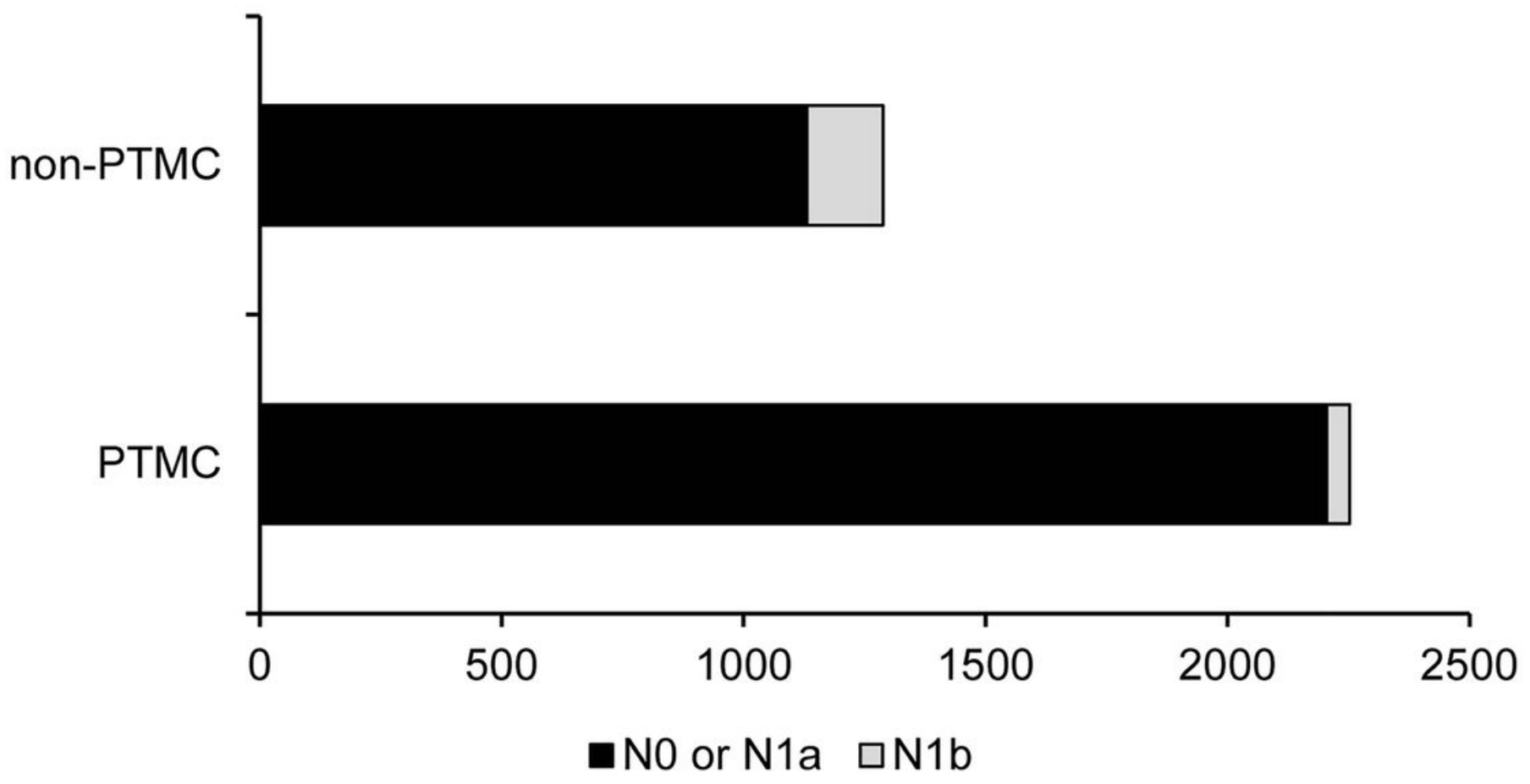

Figure 1

Comparison of the incidence of lateral lymph node metastasis between the PTMC and non-PTMC groups. PTMC, papillary thyroid microcarcinoma. 
A

\section{PTMC}

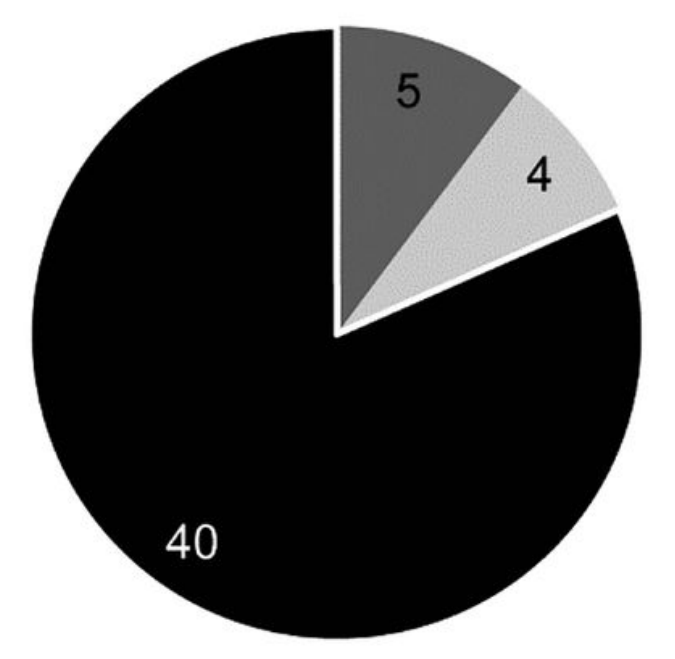

- US only $\approx$ CT only $=$ US+CT
B

\section{Non-PTMC}

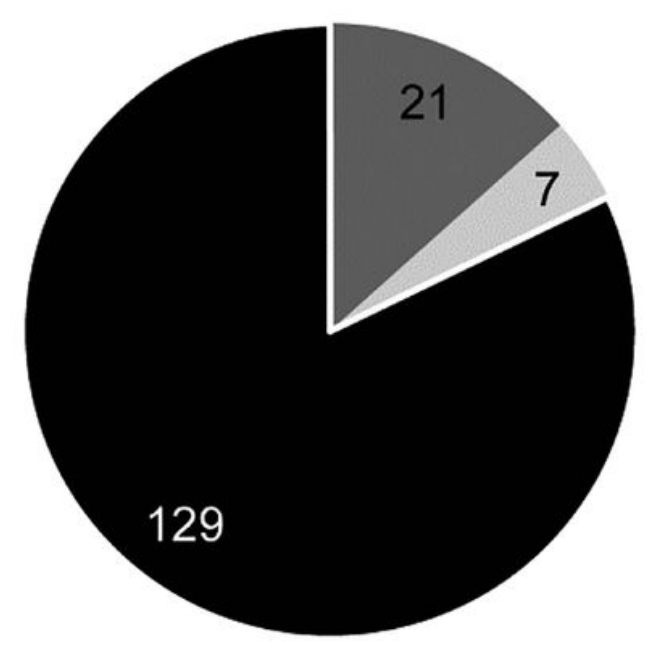

- US only $=$ CT only $-U S+C T$

Figure 2

Rate at which lateral lymph node metastasis was diagnosed on CT and ultrasonography (A) in the PTMC and (B) non-PTMC groups. CT, computed tomography; PTMC, papillary thyroid microcarcinoma. 